\title{
Fracción vascular estromal de tejido adiposo: cómo obtener células madre y su rendimiento de acuerdo a la topografía de las áreas donantes: estudio preliminar
}

\section{Stromal vascular fraction from fat tissue: obtaining stem cells and their yield according to the topography of the donor areas: previous note}

\author{
Almeida, K. A.*, Campa, A.*, Alonso-Vale, M. I. C. **, Lima, F. B.**, Daud, E. D.***, Stocchero, I. N.****
}

\section{Resumen}

La obtención de tejido adiposo supone un nuevo y prometedor mercado de trabajo para los cirujanos plásticos, ya que los bancos de tejidos escogerán de forma acertada la grasa como el medio más fácil para obtener fuentes de células madre de alto rendimiento, en la medida en que este tejido es capaz de producir al menos cinco veces más unidades formadores de colonias (UFCs) que la médula ósea. El objetivo del presente trabajo es mostrar lo que se puede esperar del tejido adiposo como origen de células adultas de fracción vacular estromal (FVE), y señalar las mejores áreas del cuerpo humano para ser elegidas como donantes de tejido adiposo, extraído mediante liposucción.

Describimos la rutina seguida para la obtención de células de FVE mediante la digestión de las muestras de tejido adiposo humano con colagenasa. En el momento de su recolección, esas células presentaban una viabilidad de $92+/-1 \%$ basada en exclusión por Azul de Trypan. Las células de FVE recontadas después de permanecer 48 horas en medio de cultivo de Eagle modificado por Dulbecco (DMEM), dentro de una cámara de Neubauer, tras lo cual el rendimiento medio de las células de FVE fue de 7,2 +/- 1,3 x $10^{3}$ células por mililitro de tejido lipoaspirado.

En conclusión, pensamos que supone un desafío en la actualidad el mejorar las estrategias para la obtención de células de FVE. Este trabajo, por ahora preliminar, muestra que las células de FVE pueden ser fácilmente obtenidas por medio de lipoaspiración. La comparación entre las diferentes áreas donantes, mostró un rendimiento $22 \%$ más alto para las células de FVE cuando el tejido adiposo había sido obtenido del tronco, en comparación a cuando lo había sido de los miembros.

Palabras clave $\begin{aligned} & \text { Células madre, Grasa, Tejido adiposo, } \\ & \text { Lipoaspiración, Lipectomía, Fracción } \\ & \\ & \text { vascular estromal }\end{aligned}$
Código numérico 19

The harvest of adipose tissue will be a promising labor marketing for plastic surgeons, since tissue banks will certainly choose fat as the easiest way to obtain a high-yield source of stem cells, as this type of tissue can produce al least five times more colony-forming units (CFUs) than bone marrow extracts.

The aim of this study is to show what can be expected from fat tissues as an origin of adult stromal vascular fraction (SVF) cells, and to evaluate the best areas to be elected as donor sites within the human body, all obtained by liposuction.

The routine to obtain SVF cells by collagenase digestion of human adipose tissue samples was described. At the time of harvest, these cells displayed a viability of $92+/-1 \%$ based on Trypan Blue exclusion, SVF cells were counted after 48 hours culture in Dulbecco's modified Eagle medium (DMEM) in a Neubauer counting chamber.

The average yield of SVF cells was 7,2+/- 1,3 x $10^{3}$ cells per milliliter of liposuctioned tissue.

As a conclusion, best strategies to obtain SVF cells are an important challenge nowadays. This study, although preliminary, showed that SVF may be easily obtained

From liposuction. Comparison among different donor sites showed a 22\% higher yield of SVF cells when fat tissue had been obtained from the trunk regions, when confronted with limbs. 


\section{Introducción}

La Cirugía Plástica, en su busca por la reparación y la mejoría estética, ha indagado en diversas fuentes a lo largo de los tiempos, en busca de las mejores soluciones, algunas todavía en fases experimentales (1-3). Actualmente la investigación en torno a las denominadas células madre adultas, muestra un camino prometedor en el campo de la Medicina y de la Cirugía Reparadora. Las células de la fracción vascular estromal (FVE) humana ya fueron aisladas de la médula ósea, del periostio, del hueso trabecular, del tejido adiposo, de la sinovial, del músculo esquelético y de la dentición decidual (4-7). En la actualidad, existen diversos métodos para aislar FVE basados en sus características físicas y físico-químicas, como por ejemplo, su adherencia a plásticos o a otros componentes de la matriz extracelular. Debido a su facilidad de aislamiento y a su extenso potencial de diferenciación, se piensa que la FVE está compuesta por tipos de células madre con buenas perspectivas para ser introducidas en breve en la práctica clínica. La identificación de varias FVE que mantiene su capacidad para diferenciarse en múltiples tipos de células, ha representado una etapa crítica en la obtención de potenciales fuentes de células para la ingeniería tisular.

El tejido adiposo representa una fuente alternativa de células madre disponible de forma rutinaria en grandes cantidades (litros) a través de liposucción. Los depósitos subcutáneos de tejido adiposo son accesibles, abundantes y reponibles, por lo que suponen una reserva potencial de células madre adultas en cada individuo. Muchos grupos de investigación, trabajando de forma independiente, han demostrado que las células madre derivadas del tejido adiposo consiguen diferenciarse in vitro en múltiples linajes, entre los cuales encontramos adipocitos, condrocitos, hepatocitos y osteoblastos, además de células endoteliales, epiteliales, hematopoyéticas, neuronales y miogénicas (8-12). Se han empleado muchos términos para identificar las células de FVE, incluyendo los de células precursoras de adipocitos, preadipocitos, células tronco adultas derivadas del subcutáneo, células estromales derivadas del tejido adiposo, células estromales adherentes derivadas del tejido adiposo, células de lipoaspirado procesado y células tronco derivadas del tejido adiposo. En este trabajo emplearemos el término células de FVE.

Aunque algunos grupos hayan centrado su atención exclusivamente en la subpoblación expandida adherente al plástico en varios estadíos, otros han trabajado con la población de células de FVE mínimamente procesadas. Por tanto, la mayor parte del conocimien- to actual ha evolucionado desde estudios que investigaron las propiedades de su progenie in vitro. Es más, grupos de esas células pueden ser inducidos a expresar el perfil bioquímico de muchos tipos de células, bajo condiciones apropiadas de cultivo in vitro. Después de su expansión in vitro, está descrito que el número de FVE in vivo aumentó de $10^{5}$ a $10^{6}$ su densidad original en el tejido adiposo. Por toro lado, los resultados varían significativamente en muchas publicaciones, probablemente porque todavía no se ha establecido ningún protocolo estándar. En consecuencia, falta una estimación más precisa del número de FVE.

El objetivo del presente trabajo fue protocolizar un método para el aislamiento, mantenimiento y rendimiento de FVE humanas obtenidas a partir de tejido adiposo de distintas regiones del tejido subcutáneo, mediante lipoaspiración, dado que las células madre derivadas del tejido adiposo presentan ventajas potenciales para su aplicación en ingeniería tisular.

\section{Material y método}

Aislamos un total de 12 muestras de tejido adiposo humano (ginecomastia bilateral $n=1$, abdomen $n=3$, "cartucheras" $n=3$, flancos $n=2$, cara interna de los muslos $n=1$ y brazos $n=2$ ), obtenidas a partir de 21 áreas tratadas en 7 pacientes consecutivos (1 hombre y 6 mujeres) sometidos a cirugía electiva (Tabla I). La edad media (media +/- desviación estándar (DP)) fue de $45+/-13$ años, con un rango de 36 a 68 años. El índice de masa corporal (IMC) fue de $24+/-3$, rango de 22 a 29. Ningún paciente presentaba infección, enfermedad o alteración endocrina. Este estudio fue aprobado y se guió por las orientaciones del Comité de Etica de la Facultad de Farmacia de la Universidad de São Paulo, Brasil. Todos los pacientes fueron informados de los objetivos y procedimientos de la investigación y firmaron su consentimiento por escrito.

\section{Preparación de los tejidos y aislamiento de las células}

Utilizamos cánulas con diámetro interno de 3 a 5 $\mathrm{mm}$, conectadas a jeringa de aspiración de $60 \mathrm{ml}$. (Fig. 1), para los procedimientos de lipoaspiración. El aislamiento de los adipocitos se hizo de acuerdo con Rodbell (13). Las muestras de tejido adiposo (20 ml) fueron fragmentadas con tijera fina e introducidas en frascos (4 g/ frasco), cada uno de ellos con un contenido de $20 \mathrm{ml}$. de DMEM estéril, $5 \mathrm{mM}$ de glucosa, $1 \%$ de albúmina sérica bovina (ASB) fracción $\mathrm{V}$, antibióticos $(100 \mu \mathrm{M} / \mathrm{ml}$ de Penicilina en $100 \mu \mathrm{g} / \mathrm{ml}$ de Estrptomicina) y $1 \mathrm{mg} / \mathrm{ml}$ de Colagenasa tipo II, ph 


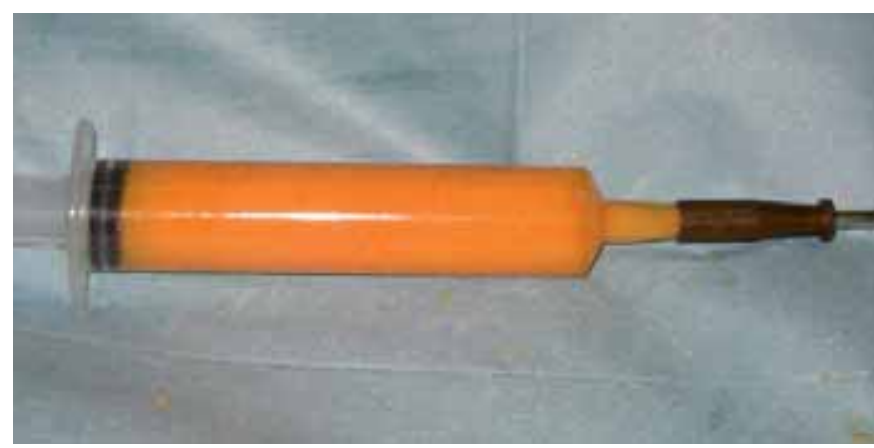

Fig. 1. Grasa lipoaspirada. Cánula con diámetro interno de $5 \mathrm{~mm}$ conectada a jeringa de $60 \mathrm{ml}$ empleada para la lipoaspiración. Gordura lipoaspirada. Cânula com diâmetro interno de $5 \mathrm{~mm}$, conectada a seringa de $60 \mathrm{ml}$, utilizada para os procedimentos de lipoaspiração.

7,4. La mezcla fue incubada en un agitador orbital a $150 \mathrm{rpm}$ durante 30 minutos a $37^{\circ} \mathrm{C}$. El material digerido fue filtrado a través de una malla plástica gruesa $\mathrm{y}$, en seguida, de una malla plástica fina, siendo después transferido a un tubo plástico cónico de $50 \mathrm{ml}$. El filtrado resultante fue centrifugado a $300 \mathrm{G}$ durante 5 minutos. Después de la centrifugación, había 3 capas reconocibles: una capa blanca fluctuante compuesta por los adipocitos, el medio de digestión y un sedimento que contenía las células FVE más los eritrocitos (Fig.2). El sedimento de FVE del fondo del tubo de centrifugado fue resuspendido en $6 \mathrm{ml}$ de tampón; entre tanto, alícuotas de $3 \mathrm{ml}$ de la última mezcla fueron colocadas en una placa de cultivo de 6 pozos. Las células fueron alimentadas con medio estromal compuesto de DMEM suplementado con $10 \%$ de suero fetal bovino (SFB) y 1\% de solución antibiótica (100 $\mu \mathrm{U} / \mathrm{ml}$ de Penicilina y $100 \mu \mathrm{g} / \mathrm{ml}$ de Estrptomicina) y mantenidas durante 48 horas en incubadora de $\mathrm{CO} 2$. Después de este periodo, el medio de incubación fue eliminado y la placa lavada cuatro veces, cada una de

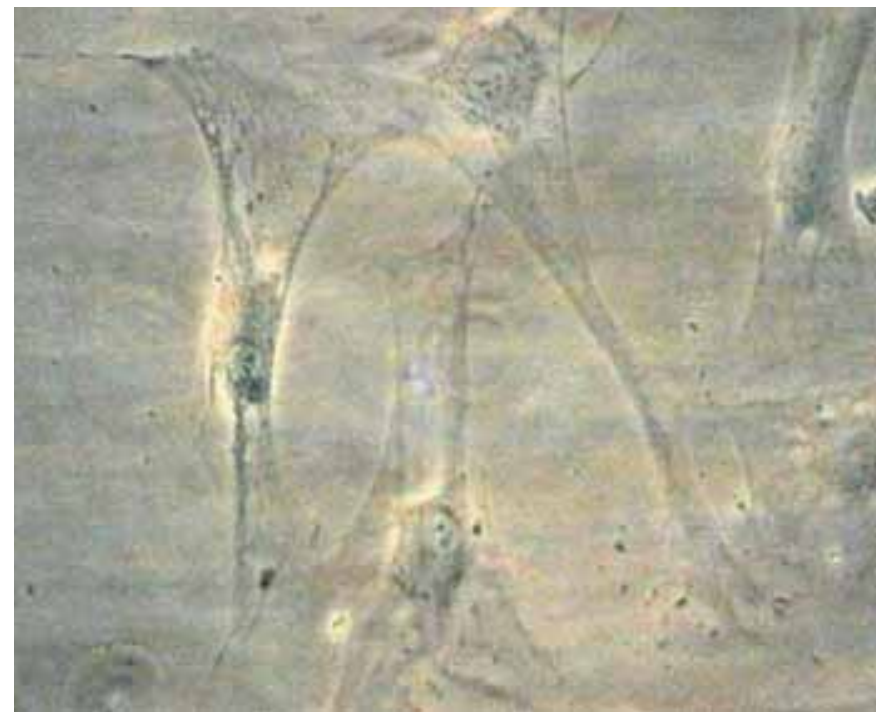

Fig. 3. Células adherentes de FVE. As células aderentes da FVE.

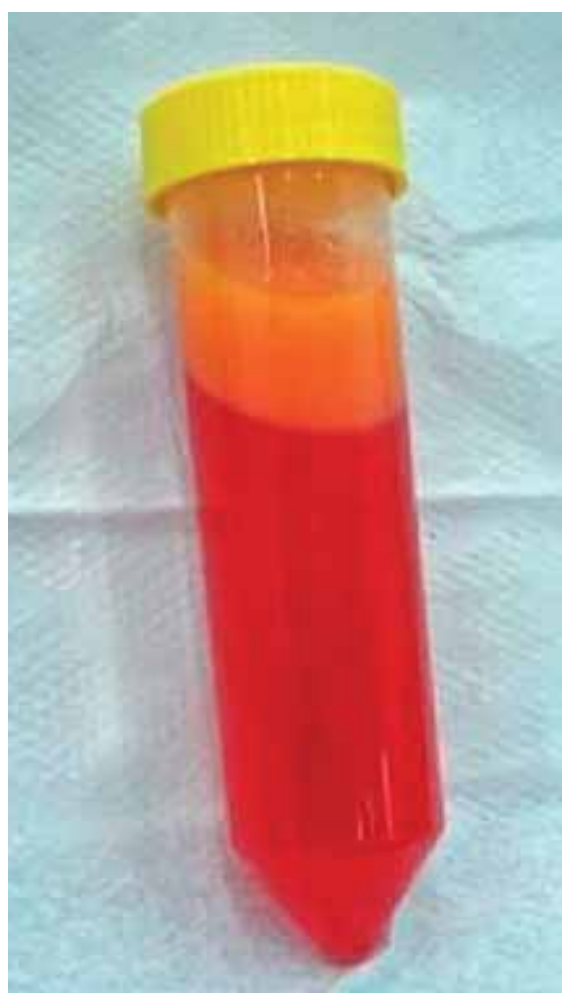

Fig. 2. Capa blanca flotante constituida por adipocitos, el medio de digestión y un sedimento que contiene las células de FVE más eritrocitos.

Uma camada branca flutuante constituída de adipócitos; o meio de digestão; e o pellet contendo as células da FVE mais eritrócitos.

ellas con $3 \mathrm{ml}$ de solución salina estéril tamponada con fosfato, a fin de eliminar cualquier célula noadherente. Las células adherentes (Fig.3) fueron tripsinizadas, recolectadas, centrifugadas a $300 \mathrm{G}$ y resuspendidas en $1 \mathrm{ml}$ de DMEM con $10 \%$ de SFB. Se contaron las células en una cámara de Neubauer. En el momento de la recolección, esas células presentaban una viabilidad de $92+/-1 \%$, basada en exclusión con Azul de Trypan. Las células fueron vueltas a colocar en placas e incubadas por un periodo adicio-

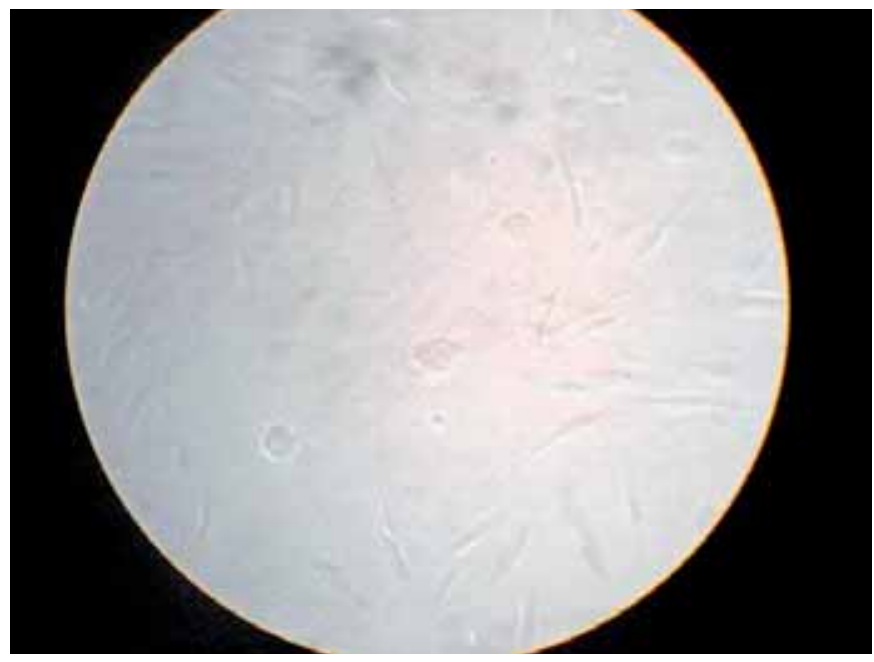

Fig.4. Células colocadas en placas e incubadas durante un periodo de 21 a 28 días, hasta obtener confluencia.

As células foram plaqueadas e incubadas por um período de 21 a 28 dias, até se obter a confluência acima. 


\begin{tabular}{|c|c|c|c|c|c|}
\hline Áreas Donantes & $\begin{array}{c}\text { Rendimento } \\
\text { Celular }(x 103) / m l \\
\text { de tejido lipoaspirado }\end{array}$ & Sexo & $\begin{array}{c}\text { Edad } \\
\text { (Años) }\end{array}$ & $\begin{array}{l}\text { Índice de } \\
\text { Masa Corporal } \\
\text { (IMC) }\end{array}$ & Viabilidad (\%) \\
\hline Ginecomastia & 8 & M & 68 & 29 & 93 \\
\hline Abdomen & 8 & M & 68 & 29 & 92 \\
\hline Abdomen & 10 & $\mathrm{~F}$ & 56 & 25 & 94 \\
\hline Abdomen & 7 & $\mathrm{~F}$ & 40 & 24 & 95 \\
\hline Abdomen & 6 & $\mathrm{~F}$ & 38 & 22 & 92 \\
\hline Flanco & 6 & $\mathrm{~F}$ & 40 & 24 & 91 \\
\hline Flanco & 9 & $\mathrm{~F}$ & 38 & 22 & 93 \\
\hline "Cartuchera" & 7 & $\mathrm{~F}$ & 40 & 24 & 91 \\
\hline "Cartuchera" & 8 & $\mathrm{~F}$ & 38 & 22 & 92 \\
\hline Cara interna del muslo & 6 & $\mathrm{~F}$ & 38 & 22 & 91 \\
\hline Cara Posterior del brazo & 5 & $\mathrm{~F}$ & 56 & 24 & 91 \\
\hline Cara Posterior del brazo & 6 & $\mathrm{~F}$ & 54 & 24 & 92 \\
\hline Medias \pm DP & $7,2 \pm 1,3$ & & $45 \pm 13$ & $24 \pm 3$ & $92 \pm 1,3$ \\
\hline Intervalo & $5-10$ & & $38-68$ & $22-29$ & $91-95$ \\
\hline
\end{tabular}

Tabla I.

nal de 21 a 28 días, hasta que se obtuvo confluencia (Fig.4).

\section{Resultados}

Los lipoaspirados de tejido adiposo subcutáneo obtenidos de 21 áreas donantes (en un total de 7 pacientes sometidos a liposucción electiva) fueron divididos en 12 muestras y procesados a través de digestión por colagenasa y centrifugación diferencial.

El rendimiento medio de las células de FVE fue de $7,2+/-1,3 \times 10^{3}$ células por mililitro de tejido lipoaspirado (Tabla I). En la época de la recolección, esas células presentaban una viabilidad de $92+/-1 \%$ basada en exclusión por Azul de Trypan.

\section{Discusión}

Se acepta comúnmente que las células madre y las células precursoras están relacionadas con el mantenimiento continuo y la reparación de la mayoría de los tejidos. Teniendo en consideración que las células madre tienen capacidad de autorrenovación y de diferenciación en múltiples linajes, éstas células son de primordial importancia para el organismo, no solo durante su desarrollo, sino también durante su madurez, con respecto a la homeostasis celular.

El medio óptimo para la obtención de células de FVE supone un importante desafío en la actualidad. Tras el estudio preliminar que hemos presentado, podemos sacar en conclusión que el rendimiento de las células obtenidas a partir del tronco humano (ginecomastia - 8,0; abdomen $-7,75$; flancos $-7,5$ ) representa una media final de $7,75 \times 10^{3} / \mathrm{ml}$ de grasa lipoaspirada, mientras que en el caso de los miembros ("cartucheras" - 7,5; cara interna de los muslos - 6,0; brazos - 5,5), el rendimiento final fue de $6,3 \times 10^{3} / \mathrm{ml}$ de grasa lipoaspirada.

\section{Conclusiones}

De acuerdo con los datos obtenidos del estudio, las áreas donantes preferidas para obtener un rendimiento $22 \%$ mayor de células de FVE se localizan en el tronco, que representa ser por tanto una mejor fuente de células madre que los miembros.

Todos estos datos, aunque preliminares, ya han influido en nuestra elección de áreas donantes de preferencia para la realización de lipoinjertos, corroborando de esta manera los hallazgos obtenidos. Continuamos realizando estudios con marcadores celulares para comprobar la descendencia de las células madre transferidas y su rendimiento a partir de diversos grupos de portadores de liposdistrofias, así como el empleo de variadas metodologías, lo cual será objeto de presentaciones futuras.

\section{AGRADECIMIENTOS}

Queremos agradecer a la Fundación de Ayuda a la Investigación del Estado de São Paulo (Fapesp) y al 
Consejo Nacional de Desarrollo Científico y Tecnológico $(\mathrm{CNPq})$ por su apoyo financiero. También a Guilherme Flosi Stocchero, estudiante de cuarto año de la Facultad de Medicina de la Universidad de São Paulo, por su ayuda en la revisión y redacción de este artículo.

\section{Dirección del autor}

Dra. Katia Aparecida Almeida

Avda. Dr. Lineu Prestes 580-Bloco 17

Laboratório de Bioquímica Clínica

055080-900 São Paulo, Brasil

e-mail: katiacidi@yahoo.com

\section{Bibliografía}

1. Montón J. Y Cols.: " Experiencia clínica en el empleo de factores de crecimiento autólogos obtenidos de plasma rico en plaquetas". Cir. plást. iberolatinoam. 2007, 33 (3): 155

2. Planas J. Y Cols.: " Supervivencia a largo plazo de los injertos grasos". Cir. plást. iberolatinoam. 2006, 32 (1): 26

3. Serra Renón y Cols.: "Uso de Factores de Crecimiento Plaquetar unidos a injertos de grasa para lipofilling facial en ritidectomía". Cir. plást. iberolatinoam. 2006, 32 (3): 191.

4. Ogawa R., Mizuno H., Watanabe A., Migita M., Shimada T., Hyakusoku: " Osteogenic and chondrogenic differentiation by adi- pose-derived stem cells harvested from Gfp transgenic mice". Biochem. Biophys. Res. Commun 2004, 313: 871.

5. Safford KM., Hicok KC., Safford SD.: "Neurogenic differentiation of murine and human adipose-derived stromal cells". Biochem. Biophys. Res. Commun 2002, 294: 371.

6. Zuk PA.,Zhu M., Ashjian P., De Ugarte DA., Huang JI., Mizuno H., Alfonso ZC, Fraser JK., Benhaim P., Hedrick MH: "Human adipose tissue is a source of multipotent stem cells". Mol. Biol. Cell 2002, 13: 4279 .

7. Zuk PA., Zhu M., Mizuno H., Huang J., Futrell JW., Katz AJ., Benhaim P., Lorenz HP., Hedrick MH.: "Multilineage cells from human adipose tissue: implications for cell-based therapies". Tissue Eng. 2001, 7: 211.

8. Gimble JM., Guilak F.: “ Adipose-derived adult stem cells: isolation, characterization and differentiation potential". Cytotherapy 2003, 5: 362 .

9. Hauner H., Enterenmann G., Wabistch M., Gaillard D., Ailaud G., Negrel R., Pfeiffer EF.: “ Promoting effect of flucocorticoids on the differentiation of human adipocyte precursor cells curtured in a chemically defined medium". J. Clin. Invest. 1989, 84: 1663.

10. Katz AJ., Tholpady A., Tholpady SS.: “ Cell surface and transcriptional characterization of human adipose-derived adherent stromal (Hadas) cells". Stem cells 2005, 23: 412.

11. Miranville A., Heeschen C., Sengenes C., Curat CA., Busse R., Bouloumie A.: " Improvement of postnatal neovascularization by human adipose tissue-derived stem cells". Circulation 2004, 110: 349.

12. Mitchel JB., Mcintosh K., Zvonic S., Garret S., Floyd ZE., Kloster A., Dihalvorsen Y., Storms RW., Goh B., Kilroy G., Wu X., Gimble JM.: “ Immunophenotype of human adipose-derived cells: temporal changes in stromal-associated and stem cell-associated markers". Stem cells 2006, 24: 376.

13. Rodbell M.: "Metabolism of isolated fat cells. Effects of hormones on glucose metabolism and lipolysis". J. Biol. Chem. 1964, 239: 357. 


\title{
Fração vascular estromal de tecido adíposo: como obter células-tronco e seu rendimiento de acordo com a topografia as áreas doadoras: nota prévia
}

\author{
Almeida, K. A.*, Campa, A.*, Cardoso Alonso-Vale, M. I. **, Bessa Lima, F.**, Dib Daud, E.***, Nogueira Stocchero, I.****
}

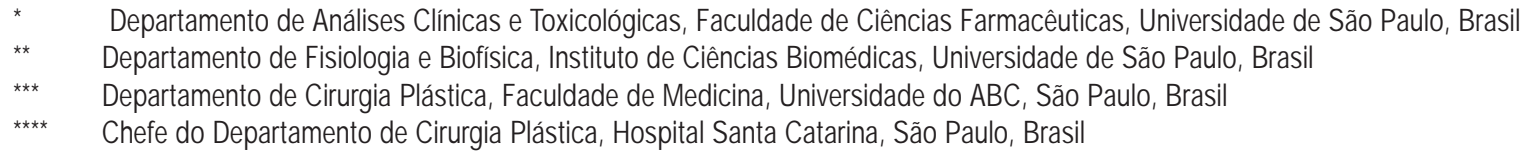

Resumo

A coleta de tecido adiposo será um novo e promissor mercado de trabalho para os cirurgiões plásticos, já que os bancos de tecidos irão certamente escolher a gordura como o meio mais fácil de se obter uma fonte de células-tronco de alto rendimento, na medida em que este tipo de tecido é capaz de produzir pelo menos cinco vezes mais unidades formadoras de colônia (UFCs) do que extratos de medula óssea. O objetivo deste estudo foi avaliar o que se pode esperar do tecido adiposo como origem de células adultas da fração vascular estromal (FVE), e avaliar as melhores áreas do corpo humano a serem eleitas como doadoras de tecido adiposo, retirado através de lipoaspiração.

Foi descrita a rotina seguida para se obter células da FVE através da digestão de amostras de tecido adiposo humano por colagenase. Na época de coleta, essas células apresentavam uma viabilidade de $92 \pm 1 \%$, baseado na exclusão por azul de tripan. As células da FVE foram contadas depois de serem deixadas por $48 \mathrm{~h}$ em meio de cultura de Eagle modificado por Dulbecco (DMEM), dentro de uma câmara de Neubauer.

O rendimento médio das células da FVE foi de 7,2 $\pm 1,3 \times 10^{3}$ células por mililitro de tecido lipoaspirado.

Conclusões: as melhores estratégias para a obtenção de células da FVE são um importante desafio atualmente. Este estudo, embora preliminar, mostrou que as células da FVE podem ser facilmente obtidas por meio de lipoaspiração. A comparação entre diferentes áreas doadoras mostrou um rendimento 22\% maior para células da FVE quando o tecido adiposo havia sido obtido da região do tronco, quando confrontado com os membros.

PALAVRAS CHAVE: Células-tronco, Gordura, Tecido adiposo, Lipoaspiração, Lipectomia, Fração vascular estromal.

Introdução

A Cirurgia Plástica, em sua busca pela reparação e melhora estética tem procurado em várias fontes, ao longo dos anos, as melhores soluções, ainda que em fases experimentaiS (1-3). Hoje, a pesquisa envolvendo as chamadas células-tronco adultas mostram um caminho promissor na área da medicina e da cirurgia reparadoras. As células da fração vascular estromal (FVE) humana já foram isoladas de medula óssea, periósteo, osso trabecular, tecido adiposo, sinóvia, músculo esquelético e dentição decídua (4-7). Vários métodos estão disponíveis atualmente para isolar a FVE, baseados em suas características físicas e físico-químicas como, por exemplo, aderência a plástico ou a outros componentes da matriz extracelular. Devido à facilidade de isolamento e extenso potencial de diferenciação, acredita-se que a FVE seja composta de tipos de células-tronco com boas chances de serem introduzidos brevemente na prática clínica. A identificação de várias FVE que mantêm a capacidade de se diferenciar em múltiplos tipos de células tem sido uma etapa crítica no fornecimento de fontes potenciais de células para a engenharia de tecidos.

$\mathrm{O}$ tecido adiposo representa uma fonte alternativa de células-tronco e está rotineiramente disponível em enormes quantidades (litros) através da lipoaspiração. Depósitos subcutâneos de tecido adiposo são acessí- veis, abundantes e passíveis de reposição, assim oferecendo um reservatório potencial de células-tronco adultas em cada indivíduo. Muitos grupos de pesquisa, trabalhando independentemente, demonstraram que células-tronco derivadas de tecido adiposo conseguem se diferenciar in vitro em múltiplas linhagens, dentre as quais adipócitos, condrócitos, hepatócitos e osteoblastos, além de células endoteliais, epiteliais, hematopoéticas, neuronais e miogênicas (8-12). Muitos termos têm sido usados para identificar as células da FVE, incluindo células precursoras de adipócitos, pré-adipócitos, células-tronco adultas derivadas do subcutâneo, células estromais derivadas de tecido adiposo, células estromais aderentes derivadas de tecido adiposo, células de lipoaspirado processado, e células-tronco derivadas de tecido adiposo. Neste trabalho, usaremos o termo células da FVE.

Embora alguns grupos tenham focado sua atenção exclusivamente na subpopulação expandida aderente a plástico em vários estágios, outros têm trabalhado com a população de células da FVE minimamente processadas. Portanto, muito do conhecimento atual evoluiu de estudos que investigaram as propriedades de sua progênie in vitro. Além disso, grupos dessas células podem ser induzidos a expressar o perfil bioquímico de muitos tipos de células, sob condições apropriadas de cultura in vitro. Depois da expansão in vitro, foi relatado que o número de FVE in vivo aumentou de $10^{5}$ a $10^{6}$ vezes sua densidade original em tecido adiposo. Entretanto, os resultados variam significativamente em muitas publicações, provavelmente porque ainda não foi estabelecido nenhum protocolo padrão. Conseqüentemente, está faltando uma estimativa mais precisa do número de FVE.

$\mathrm{O}$ objetivo deste estudo foi padronizar um procedimento para o isolamento, manutenção e rendimento de FVE humanas obtidas a partir de tecido adiposo de distintas regiões do subcutâneo, através de cirurgia de lipoaspiração, dado que células-tronco derivadas de tecido adiposo exibem vantagens potenciais para aplicações em engenharia de tecidos.

\section{Materiais e metodos}

Um total de 12 amostras de tecido adiposo humano (ginecomastia bilateral $n=1$, abdome $n=3$, culotes $n=3$, flancos $n=2$, face interna das coxas $n=1$, e braços $n=2$ ), obtido a partir de 21 áreas tratadas em sete pacientes sadios (um homem e seis mulheres) submetidos a cirurgia eletiva, foi analisado (Tabela I). A idade média [média \pm desvio-padrão (DP)] foi de $45 \pm 13$ anos, e variou entre 38 e 68 anos. O índice de massa corpórea (IMC) médio foi de $24 \pm 3$, e variou entre 22 e 29 . Nenhum paciente apresentava sepse, malignidades ou distúrbios endócrinos. Este estudo foi aprovado e respeitou as orientações do Comitê de Ética da Faculdade de Ciências Farmacêuticas da Universidade de São Paulo, Brasil. Todos os pacientes foram informados dos objetivos e procedimentos da investigação, e nos forneceram seu consentimento por escrito.

\section{Preparação dos tecidos e isolamento das células}

Utilizamos cânulas com diâmetro interno de 3 a $5 \mathrm{~mm}$, conectadas a seringa de $60 \mathrm{~mL}$ (Fig. 1), para os procedimentos de lipoaspiração. O isolamento dos adipócitos foi feito de acordo com Rodbell (13). Amostras 
de tecido adiposo $(20 \mathrm{~mL})$ foram picadas com tesoura fina e adicionadas a frascos (4g/frasco), cada um contendo $20 \mathrm{~mL}$ de DMEM estéril, $5 \mathrm{mM}$ de glicose, $1 \%$ de albumina sérica bovina (ASB) fração $\mathrm{V}$, antibióticos $(100 \mu \mathrm{M} / \mathrm{mL}$ de penicilina e $100 \mu \mathrm{g} / \mathrm{mL}$ de estreptomicina) e $1 \mathrm{mg} / \mathrm{mL}$ de colagenase tipo II, em pH 7,4. A mistura foi incubada em um agitador orbital a $150 \mathrm{rpm}$ durante 30 minutos a $37^{\circ} \mathrm{C}$. O material digerido foi filtrado através de uma malha plástica grossa e, em seguida, uma malha plástica fina, sendo então transferido para um tubo plástico cônico de $50 \mathrm{~mL}$. O filtrado resultante foi centrifugado a $300 \mathrm{G}$ por 5 minutos. Depois da centrifugação, três camadas distintas eram reconhecíveis: uma camada branca flutuante composta pelos adipócitos; o meio de digestão; e um pellet contendo as células da FVE mais eritrócitos (Fig. 2). O pellet de FVE ao fundo da centrífuga foi ressuspendido em $6 \mathrm{~mL}$ de tampão; então, alíquotas de $3 \mathrm{~mL}$ da última mistura foram colocadas em uma placa de cultura de seis poços. As células foram nutridas com meio estromal composto de DMEM suplementado com $10 \%$ de soro fetal bovino (SFB) e $1 \%$ de solução antibiótica $(100 \mu \mathrm{U} / \mathrm{mL}$ de penicilina e $100 \mu \mathrm{g} / \mathrm{mL}$ de estreptomicina) e mantidas por $48 \mathrm{~h}$ em uma incubadora de $\mathrm{CO}_{2}$. Após este período, o meio de incubação foi removido e a placa foi lavada quatro vezes, cada lavagem sendo feita com $3 \mathrm{~mL}$ de solução salina estéril tamponada com fosfato, a fim de remover quaisquer células não-aderentes. As células aderentes (Fig. 3) foram tripsinizadas, recoletadas, centrifugadas a $300 \mathrm{G}$ e ressuspendidas em $1 \mathrm{~mL}$ de DMEM com $10 \%$ de SFB. As células foram contadas em uma câmara de Neubauer. Na época da coleta, essas células apresentavam uma viabilidade de $92 \pm 1 \%$, baseado em exclusão por azul de tripan. As células foram replaqueadas e incubadas por um período adicional de 21 a 28 dias, até a confluência ser atingida (Fig. 4).

\section{Resultados}

Lipoaspirados de tecido adiposo subcutâneo obtidos de 21 áreas doadoras (em um total de 7 pacientes submetidos a cirurgia eletiva de lipoaspiração) foram divididos em 12 amostras e processados através de digestão por colagenase e centrifugação diferencial.

O rendimento médio das células da FVE foi de 7,2 $\pm 1,3 \times 10^{3}$ células por mililitro de tecido lipoaspirado (Tabela I). Na época da coleta, essas células apresentavam uma viabilidade de $92 \pm 1 \%$, baseado em exclusão por azul de tripan.

\section{Discussão}

É comumente aceito que células-tronco e células precursoras estão envolvidas na manutenção contínua e reparo da maioria dos tipos de tecidos. Levando em consideração que as células-tronco têm capacidade de auto-renovação e de diferenciação em múltiplas linhagens, esta classe de células é de primordial importância para um organismo, não apenas durante o desenvolvimento, mas também durante a maturidade, em relação à homeostase celular.

O melhor meio de se obter essas células da FVE é um importante desafio atualmente. Após este estudo preliminar, podemos concluir que o rendimento das células obtidas a partir do tronco humano (ginecomastia - 8,0; abdome - 7,75; e flancos - 7,5) apresentou uma média final de $7,75 \times 10^{3} / \mathrm{mL}$ de gordura lipoaspirada, enquanto que, no caso dos membros humanos (culotes $-7,5$; face interna das coxas $-6,0$; e braços $-5,5$ ), o rendimento médio final foi de $6,3 \times 10^{3} / \mathrm{mL}$ de gordura lipoaspirada.

\section{Conclsões}

De acordo com este estudo, as áreas doadoras preferidas para se obter um rendimento $22 \%$ maior de células da FVE estão localizadas no tronco, que se mostrou uma fonte melhor de células-tronco do que os membros.

Tais dados, ainda que preliminares, já têm influído em opções de áreas doadoras preferenciais para lipoenxertias, corroborando os achados apurados. Os estudos com marcadores celulares para comprovarem a descendência das células-tronco transferidas, o seu rendimento a partir de diversos grupos de portadores de lipodistrofias, bem como o uso de variadas metodologias, continuam a serem feitos, sendo objeto de apresentação futura.

\section{AGRADECIMENTOS}

Os autores gostariam de agradecer à Fundação de Amparo à Pesquisa do Estado de São Paulo (Fapesp) e ao Conselho Nacional de Desenvolvimento Científico e Tecnológico (CNPq), por seu apoio financeiro. E também a Guilherme Flosi Stocchero, estudante do quarto ano da Faculdade de Medicina da Universidade de São Paulo, por seu auxílio na execução e redação deste artigo.

\begin{tabular}{|c|c|c|c|c|c|}
\hline Áreas Doadoras & $\begin{array}{c}\text { Rendimento } \\
\text { Celular }\left(\mathbf{x}^{3} \mathbf{3}^{3}\right) / \mathrm{mL} \\
\text { de tecido lipoaspirado }\end{array}$ & Sexo & $\begin{array}{l}\text { Idade } \\
\text { (Anos) }\end{array}$ & $\begin{array}{c}\text { Índice de } \\
\text { Massa Corpórea } \\
\text { (IMC) }\end{array}$ & Viabilidade $(\%)$ \\
\hline Ginecomastia & 8 & M & 68 & 29 & 93 \\
\hline Abdome & 8 & $\mathrm{M}$ & 68 & 29 & 92 \\
\hline Abdome & 10 & $\mathrm{~F}$ & 56 & 25 & 94 \\
\hline Abdome & 7 & $\mathrm{~F}$ & 40 & 24 & 95 \\
\hline Abdome & 6 & $\mathrm{~F}$ & 38 & 22 & 92 \\
\hline Flanco & 6 & $F$ & 40 & 24 & 91 \\
\hline Flanco & 9 & $\mathrm{~F}$ & 38 & 22 & 93 \\
\hline Culote & 7 & $F$ & 40 & 24 & 91 \\
\hline Culote & 8 & $\mathrm{~F}$ & 38 & 22 & 92 \\
\hline Face interna da coxa & 6 & $\mathrm{~F}$ & 38 & 22 & 91 \\
\hline Face posterior do braço & 5 & F & 56 & 24 & 91 \\
\hline Face posterior do braço & 6 & $\mathrm{~F}$ & 54 & 24 & 92 \\
\hline Médias $\pm \mathrm{DP}$ & $7,2 \pm 1,3$ & & $45 \pm 13$ & $24 \pm 3$ & $92 \pm 1,3$ \\
\hline Intervalo & $5-10$ & & $38-68$ & $22-29$ & $91-95$ \\
\hline
\end{tabular}

Tabela I. 


\title{
Comentario al trabajo ufracción vascular estromal de tejido adiposo: cómo obtener células madre y su rendimiento de acuerdo a la topografía de las áreas donantes: estudio preliminarı
}

\author{
Montón Echeverría J \\ Facultativo Especialista de Área (FEA) / Adjunto. Servicio de Cirugía Plástica y Reparadora. Hospital Nuestra Seño- \\ ra del Perpetuo Socorro.Profesor Asociado Facultad de Medicina. Universidad de Castilla-La Mancha.Complejo Hospi- \\ talario Universitario de Albacete. Albacete. España.
}

Quisiera felicitar a los autores por el trabajo presentado. Aunar la práctica clínica diaria con la investigación no siempre es sencillo, pero desde el momento en que existe la posibilidad de colaborar con otros Departamentos que pueden completar la tarea, ésta se facilita sobremanera.

Los autores presentan un estudio preliminar sobre el rendimiento en la obtención de células madre adultas a partir de lipoaspiración en diversas localizaciones topográficas. La introducción de los términos, por ambigua en la propia literatura científica, precisa cierta simplificación que sólo podrá completarse con el paso del tiempo y nuevos estudios. El término empleado de fracción vascular estromal (FVE) hace referencia a células del tejido conectivo localizadas alrededor del árbol vascular, e incluye células con características comunes a las células madre (stem cells). Recordemos que existen dos grupos de células madre: totipotenciales y pluripotenciales.

Las células madre pluripotenciales no son capaces de generar cualquier tejido, pero sí aquellos derivados de la misma capa germinal (ectodermo, mesodermo o endodermo). En este sentido, las céulas madre mesenquimales (mesenchymal stem cells) pueden localizarse en tejido adiposo, médula ósea, dentición caduca o incluso sangre periférica. Más aún, hay estudios que demuestran la capacidad de proliferación hacia células derivadas de líneas diferentes $(1,2)$. La FVE es una porción de tejido adiposo donde reside una enorme población de células pluripotenciales mesenquimales(3).

Hay que recordar que un artículo científico debe ser, entre otros, reproducible al máximo. La descripción completa de, por ejemplo, el aparataje o los preparados enzimáticos que los autores han empleado (datos comerciales, laboratorios, etc.) sería un punto a completar en ulteriores estudios.

El tamaño muestral, al tratarse de un estudio preliminar, es reducido, y ello es la causa probablemente de que la diferencia que se comenta en el artículo entre densidad de células progenitoras en tronco frente a extremidades, aunque de cierta magnitud, no alcance el nivel de significación estadística que nos permita afirmar que, efectivamente, hay diferencias entre los grupos.

Los autores no hacen referencia a la preparación de las lipoaspiraciones, si bien considero que es importante contar con datos como si emplearon o no anestésico, vasoconstrictor o algo tan trivial como el medio de dilución. Recordemos que no hace tanto se hablaba de utilizar exclusivamente Ringer-Lactato a fin de evitar toxicidad celular, si bien en la actualidad tiende a emplearse una solución a base de suero fisiológico (4). Desde luego, una viabilidad inicial del 92\% es muy elevada, aunque este valor sea solamente "in vitro".
Con los datos que se facilitan en el artículo no se puede deducir que la cantidad de tejido adiposo lipoaspirado en las diferentes intervenciones sea equiparable, puesto que aunque se especifiquen los resultados como densidad de células de FVE por ml de tejido aspirado, desconocemos la proporción tejido aspirado / solución infiltrada. Obviamente no es equiparable la proporción de células en una lipoaspiración seca que tras una técnica tumescente, a menos que para los cálculos esto se tenga en cuenta y así se indique.

El grupo de pacientes es un tanto heterogéneo, y pienso que para posteriores estudios deberán ajustar más la población objeto. Les recomendaría excluir varones entre sus pacientes, o al menos excluir sesgos debidos a la diferencia de sexos, ajustando por este parámetro. La situación hormonal o el propio IMC elevado pueden condicionar una mayor proliferación celular, y además la relación entre causa y consecuencia suele ser biunívoca (3).

Este estudio preliminar debe sin duda servir para animar a sus autores y a otros grupos a continuar en esta apasionante y prometedora línea de investigación sobre la obtención de "células progenitoras derivadas del tejido adiposo". Propondría desde aquí utilizar este término, al menos en castellano, para referirnos a las células de FVE, y que puede emplearse tanto para la fracción estromal vascular obtenida mediante lipoaspiración como mediante lipectomía.

No me resta sino alabar la audacia de los autores a la hora de elegir esta línea de investigación. Aunque es evidente que el futuro a corto plazo pasa por emplear, optimizadas, éstas y otras técnicas basadas en la recolección de células progenitoras autólogas, los comienzos siempre son complicados.

\section{Bibliografía}

1. Qiling He, Chao Wan and Gang Li.: "Concise Review: Multipotent Mesenchymal Stromal Cells in Blood". Stem Cells 2007;25: 69.

2. JA Villena1, B Cousin1, L Pénicaud1 and L Casteilla: "Adipose tissues display differential phagocytic and microbicidal activities depending on their localization”. Int J Obes Relat Metab Disord. 2001;25(9):1275.

3. Dugail I, Dupuy F, Quignard-Boulangé A.: "Role of adipocyte precursors in the initiation of nutritional obesity before weaning". Reprod Nutr Dev. 1985;25(1B): 189.

4. Kaufman MR, Bradley JP, Dickinson B, Heller JB, Wasson K, O'Hara C, Huang C, Gabbay J, Ghadjar K, Miller TA.: "Autologous fat transfer national consensus survey: trends in techniques for harvest, preparation, and application, and perception of shortand long-term results". Plast Reconstr Surg. 2007;119(1):323. 


\section{Respuesta al comentario del Dr. Montón Echeverría J.}

\section{Dr. Ithamar N. Stocchero}

Felicito al Dr. Montón Echeverría por la claridad de sus comentarios y estoy completamente de acuerdo con sus observaciones.

Empleamos el termino fracción vascular estromal por razones técnicas. Solo se debe utilizar el termino células tronco a partir del aislamiento y expansión de las mismas, lo que solo puede configurarse cuando estas células se adhieren al cristal o al plástico de los tubos de cultivo. La sugerencia de utilizar la denominación `células progenitoras derivadas del tejido adiposo' en las lenguas latinas, que es bienvenida, ya tiene su equivalente en ingles, ASCS (Adipose Derived Stem Cells).

Sabemos que no hemos descrito algunos puntos, pero como se realizan de forma sistemática en todos los casos (infiltración de suero fisiológico con epinefrina al 1. 500.000 en proporción 0,5 a 1 en el tejido adiposo antes de la liposucción, empleo de los mismos agentes químicos cuyos nombres no hemos divulgado puesto que no tenemos ningún soporte comercial, técnica clásica de aislamiento descrita por Rodbell y reproducible desde hace 45 años), pero consideramos que dichos factores, comunes y constantes, no ejercen influencia en los datos comparados.

En cuanto a la presencia de un individuo de sexo masculino en la muestra, fue introducido para representar el porcentaje aproximado de nuestros pacientes de este sexo que se someten a liposucción
(14\%), además de servirnos para analizar un área, la ginecomastia, que representa una zona en la que las células grasas podrían estar en un proceso acelerado de multiplicación, en comparación con la grasa extraída de la zona abdominal del mismo paciente. Como vemos en la Tabla I, esta diferencia no se presentó en el caso estudiado.

Nuestro trabajo está en franca continuación, comparando también los rendimientos cuando se realiza infiltración de vasoconstrictor (lo que inicialmente parece no interferir con el resultado), rendimientos postcongelación y otros. En cuanto obtengamos una diferencia estadísticamente significativa, haremos una divulgación completa de los resultados.

Como estos estudios, para nuestros modelos de investigación, suponen un costo elevado, la obtención de los presentes resultados, suficientes para una Nota Previa, y la voluntad de presentar una idea nueva y de constatar una realidad, nos animó a compartirlos con todos los posibles interesados en este campo, estimulando la comparación e incluso el debate.

Nos sentimos honrados con las palabras de entusiasmo del Dr. Montón Echeverría para continuar con la investigación y por la oportunidad que nos brindan la Dra. M. del Mar Vaquero y el Cuerpo Editorial de nuestra Revista Iberolatinoamericana, que merece ciertamente toda nuestra atención.

\section{Réplica ao comentário do Dr. Montón Echeverría J.}

\section{Dr. Ithamar N. Stocchero}

Felicito ao Doctor Monton Echeverria pela lucidez de seus comentários e concordo na plenitude com suas observações.

O termo fração vascular estromal foi utilizado por razões técnicas: só se deve utilizar o termo células-tronco a partir do isolamento e expansão das mesmas, o que só pode ser configurado quando tais células já aderiram ao vidro ou ao plástico das garrafas de cultivo. A sugestão de utilizar-se o nome "células progenitoras derivadas del tejido adiposo" em línguas latinas, bem vinda, já tem o seu equivalente em inglês: ASCS (Adipose-Derived Stem Cells).

Sabemos que deixamos de descrever algumas informações, mas como elas ocorreram de forma sistemática em todos os casos (infiltração de soro fisiológico com epinefrina a 1:500,000, na proporção de 0,5:1, no tecido adiposo antes da lipoaspiração ou lipectomia; uso dos mesmos agentes químicos, cujos nomes não foram divulgados por não termos qualquer suporte por parte de Laboratórios; técnica clássica de isolamento, descrita por Rodbell, e reproduzível há 45 anos), consideramos que tais fatores, comuns e constantes, não exerceriam influência na comparação.

Quanto à presença de um indivíduo do sexo masculino, foi colocado por representar o percentual aproximado de nossos pacientes deste sexo em cirurgias de lipoaspiração (14\%), além de analisarmos uma área que apresenta um crescimento de certa forma atípico (ginecomastia), na qual procuramos uma eventual diferença, comparada com o abdome do mesmo paciente, o que não aconteceu, no caso analisado (Tabela I).

O nosso trabalho está em franca continuidade, comparando, também, rendimentos com e sem a infiltração de vasoconstritor (o que parece, inicialmente, não interferir no resultado), rendimentos póscongelamento, e outros. Assim que tivermos significância estatística, faremos a divulgação plena dos resultados.

Como estes estudos, para os nossos padrões de pesquisa, envolvem custos altos, a obtenção de tais resultados, suficientes para uma Nota Prévia, e a vontade de expressar uma nova idéia e uma constatação, nos entusiasmou a dividi-los com os possíveis interessados na Área, estimulando a comparação e o debate, inclusive.

Nós nos sentimos honrados com as palavras de entusiasmo à continuidade da pesquisa manifestada pelo Dr. Monton Echeverria, e pela oportunidade a nós deferida pela Dra. Mar Vaquero e Corpo Editorial desta nossa Revista Iberolatinoamericana, que merece, certamente, toda a nossa atenção em publicações. 